\title{
Experimental Study of Owl-Like Airfoil Aerodynamics at Low Reynolds Numbers
}

\author{
Masayuki Anyoji', Shotaro Wakui', Daiki Hamada', Hikaru Aono² \\ ${ }^{1}$ Interdisciplinary Graduate School of Engineering Sciences, Kyushu University, Fukuoka, Japan \\ ${ }^{2}$ Department of Mechanical Engineering, Tokyo University of Science, Tokyo, Japan \\ Email: anyoji.masayuki.660@m.kyushu-u.ac.jp,2ES16303R@s.kyushu-u.ac.jp,2ES17319N@s.kyushu-u.ac.jp, aono@rs.tus.ac.jp
}

How to cite this paper: Anyoji, M., Wakui, S., Hamada, D. and Aono, H. (2018) Experimental Study of Owl-Like Airfoil Aerodynamics at Low Reynolds Numbers. Journal of Flow Control, Measurement \& Visualization, 6, 185-197.

https://doi.org/10.4236/jfcmv.2018.63015

Received: March 7, 2018

Accepted: July 9, 2018

Published: July 12, 2018

Copyright () 2018 by authors and Scientific Research Publishing Inc. This work is licensed under the Creative Commons Attribution International License (CC BY 4.0).

http://creativecommons.org/licenses/by/4.0/

\begin{abstract}
This study experimentally investigates aerodynamic characteristics and flow fields of a smooth owl-like airfoil without serrations and velvet structures. This biologically inspired airfoil design is intended to serve as the main-wing for low-Reynolds-number aircrafts such as micro air vehicles. Reynolds number dependency on aerodynamics is also evaluated at low Reynolds numbers. The results of the study show that the owl-like airfoil has high lift performance with a nonlinear lift increase due to the presence of a separation bubble on the suction side. A distinctive flow feature of the owl airfoil is a separation bubble on the pressure side at low angles of attack. The separation bubble switches location from the pressure side to the suction side as the angle of attack increases and is continuously present on the surface within a wide range of angles of attack. The Reynolds number dependency on the lift curves is insignificant, although differences in the drag curves are especially pronounced at high angles of attack. Eventually, we obtain the geometric feature of the owl-like airfoil to increase aerodynamic performance at low Reynolds numbers.
\end{abstract}

\section{Keywords}

Owl Wing, Low Reynolds Number, Aerodynamics, Separation Bubble

\section{Introduction}

Biomimetics includes the concepts and principles acquired from nature for application in science and engineering such as in aerodynamic and fluid control devices. The serrated wing of the barn owl is a representative example. Many studies have been reported that using a serrated design on the leading edge of an aircraft wing reduces aerodynamic noise [1] [2] [3]. In addition, the barn owl 
glides to hunt its prey at $2.5 \mathrm{~m} / \mathrm{s}$ to $5.0 \mathrm{~m} / \mathrm{s}$, which corresponds with the flight Reynolds number range of 30,000 - 90,000 based on the mean chord length of $180 \mathrm{~mm}$ [4]. The aerospace community is interested in the low-Reynolds-number flight and flapping flight for developing micro air vehicles (MAVs) [5] and Martian atmospheric flight vehicles [6] [7] whose cruise Reynolds number is in the order of $O\left(10^{4}\right)$. Using a three-dimensional laser scanner, Liu et al. [8] measured the surface geometry of several avian wings including the owl wing to extract the wings' geometrical properties including the camber line, thickness distribution, planform, chord distribution, and twist distributions. Compared with other avian wings, the cross-sectional shape of the owl wing is a unique structure that is characterized by very thin wing thickness and high camber. Schmitz et al. described an airfoil with geometric features that achieves high aerodynamic performance at low Reynolds numbers [9] [10], which coincides with the geometric features of the owl wing. This present study investigates the aerodynamic characteristics of an owl-like airfoil that approaches the flight Reynolds numbers of an owl wing. However, unlike the actual owl wing that is characterized by serrations, a velvet and training-edge fringe structure [11], and aeroelastically deformable feathers, the owl-like airfoil design of this study is solid and smooth. Kondo et al. [12] conducted two-dimensional laminar analyses of the smooth owl-shape airfoil provided by Liu et al. [8] at $\mathrm{Re}=23,000$. They investigated the basic aerodynamic characteristics and flow fields around the airfoil and compared that with the Ishii airfoil [13], which is considered the frontrunner candidate for the main-wing airfoil of the Japanese Mars airplane. However, the airfoil shape of their computational model is virtual since zero thickness is assumed in the vicinity of the trailing edge. Furthermore, a laminar separation is likely to occur with such a low Reynolds number along with the formation of a laminar separation bubble when the separated share layer transits from laminar to turbulent and reattaches to the surface [14]. A behavior of the laminar separation bubble directly connects to the aerodynamic performance since it forms a strong negative pressure region on the surface and causes a nonlinear lift curve [15]. Thus, experimental investigations are required because the prediction accuracy of the reattachment point of the separation bubble is insufficient in the two-dimensional laminar analysis.

With a view to the main-wing airfoil design such as MAVs based on the biomimetics, the aim of the present work is to experimentally determine the Reynolds number dependence on the aerodynamic performance of an owl-like airfoil at low Reynolds numbers and to investigate the flow fields that lead to aerodynamic change using flow visualization.

\section{Experimental Setup and Condition}

\subsection{Owl-Like Airfoil}

The geometry of the test model airfoil in this study and that of the owl airfoil given by Liu et al. [8] are compared in Figure 1. The cross section of the owl 


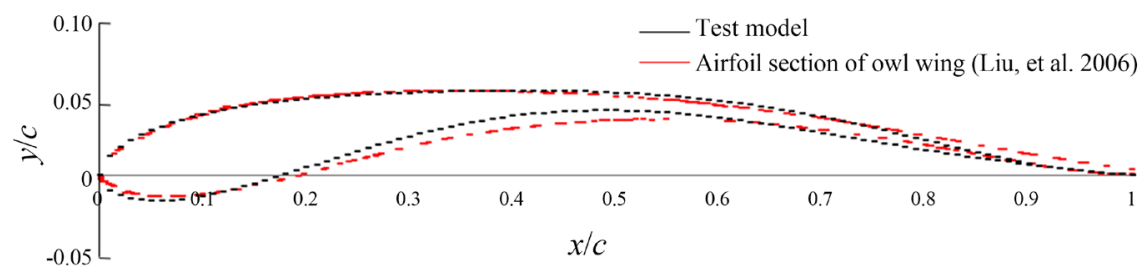

Figure 1. Airfoil section of owl-like wing (Black dash line: Test model geometry, Red dash line: Measured owl wing geometry).

airfoil (denoted by the red dash line) in Figure 1 is measured at $40 \%$ of the semi-span of the actual owl wing $(2 z / b=0.4)$. The maximum airfoil thickness is as thin as $5.5 \%(t / c=0.055)$ at $x / c=0.11$. The wing thickness near the feathery trailing edge $(x / c>0.9)$ is zero. Since it is exceedingly difficult to create an airfoil model of this thickness dimension to withstand the wind tunnel test, a test model made of balsa wood with a thickness of $1.25 \%$ near the trailing edge, a chord length of $80 \mathrm{~mm}$, and a span length of $180 \mathrm{~mm}$ was created, as shown in Figure 2. There were also slight differences in shape on the lower surface of the model $(x / c=0.2-0.6)$. Regardless, the baseline of the owl wing was reproduced as closely as possible and any effects on measurement were negligible since deviation in design was less than $1 \%$ of the chord length. The geometry of the test model, which is denoted by the black dash line in Figure 1, is measured using a noncontact three-dimensional laser scanning system (KONICA MINOLTA RANGE7) with $4 \mu \mathrm{m}$ measurement accuracy.

\subsection{Aerodynamic Force Measurement}

A series of experiments were performed using an open-circuit low-speed wind tunnel at Kyushu University. The rectangular cross section of the test section was $180 \mathrm{~mm} \times 360 \mathrm{~mm}$. The test section was covered on every side with an acrylic sidewall. Turbulence intensity was approximately $0.3 \%$ at $5.0 \mathrm{~m} / \mathrm{s}$. Lift and drag measurements were made by vertically mounting the airfoil model on the test section and attaching a three-component microforce balance system (LMC-3501-5N, NISSHOELECTRIC-WORKS) at the bottom of the test section. Each related load of the balance system was set at $5 \mathrm{~N}$ for the lift and drag forces, and $0.5 \mathrm{Nm}$ for the momentum. The uncertain accuracy of the aerodynamic force measurements is estimated at approximately $0.2 \%$, based on our micro-force calibration tests. Lift and drag forces were calibrated beforehand using standard weights. The test model was installed in the test section with a gap of $0.5 \mathrm{~mm}$ between the sidewall and the model tip in accordance with Rae and Pope [16], who indicated that the gap should be lower than $0.5 \%$ of the span, and Burns and Mueller [17], who showed that gap sizes between 0.1 and $1.4 \mathrm{~mm}$ were acceptable and should not affect the results.

\subsection{Flow Visualization}

The same setup for the test model was used to perform the smoke visualization 


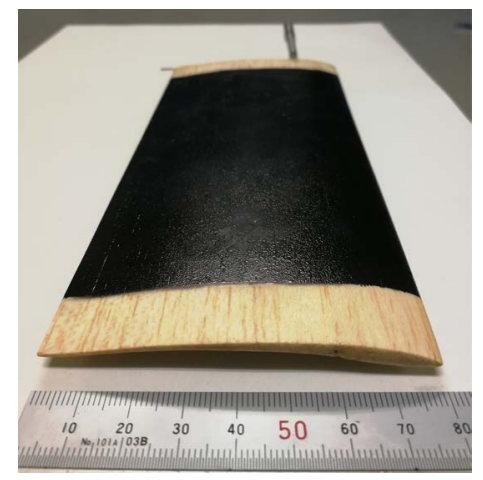

Figure 2. Test model of owl wing.

experiments using the smoke wire technique. Two nichrome wires with $0.1 \mathrm{~mm}$ diameter were horizontally set up at the inlet of the test section and coated with liquid paraffin as the working substance. The wires were located $75 \mathrm{~mm}$ forward of the leading edge of the airfoil and perpendicular to the leading edge. An alternating electric voltage from a Volt slider (S-130-10, YAMABISHI ELECTRICS) was applied across the wires to generate smoke. A green laser with a $2 \mathrm{~W}$ output (SDL-532-2000T, Scitec Instruments Ltd.) was used as a light source. The smoke-line was recorded using a high-speed video camera (Miro C110, Phantom) at a frame rate of 400 frames per second with an exposure time of $2400 \mu$ s, and image resolution of $1280 \times 1024$ pixels.

\subsection{Experimental Condition}

Aerodynamic force measurements were conducted in the Reynolds number range 23,000 - 60,000. The Reynolds number was based on the chord length of the test model. Since the cruise Reynolds number of the Mars airplane currently under consideration by the Japan Aerospace Exploration Agency is $\operatorname{Re}=23,000$, we recognized that value as a standard Reynolds number. The corresponding free-stream velocities for each Re are shown in Table 1 . The angle of attack $(\alpha)$ was changed from $\alpha=-10 \mathrm{deg}$ to $20 \mathrm{deg}$ in $1 \mathrm{deg}$ increments. The flow visualization was performed on each of the upper and lower surfaces of the wing at Re $=23,000$. For $\operatorname{Re}=30,000$, only the flow field on the suction side was visualized.

\section{Results and Discussions}

\subsection{Aerodynamic Characteristics}

Figure 3 illustrates the aerodynamic force characteristics at $\mathrm{Re}=23,000$. Error bars indicate standard deviations of three repeat measurements. As shown in Figure 3, the standard deviations are negligibly small, indicating highly reproducible measurement results. For purpose of comparison, CFD results of the two-dimensional laminar analyzes [12] were also plotted.

With respect to lift measurements, the experimental results in Figure 3(a) show the test model to be in reasonable agreement with CFD data, although a slight difference was observed at $\alpha=5 \mathrm{deg}$. The lift coefficients increased almost 
Table 1. Corresponding Reynolds number and flow velocity.

\begin{tabular}{cccccc}
\hline Reynolds Number & 23,000 & 30,000 & 40,000 & 50,000 & 60,000 \\
\hline Flow Velocity $(\mathrm{m} / \mathrm{s})$ & 4.7 & 6.0 & 8.0 & 10.0 & 12.0 \\
\hline
\end{tabular}

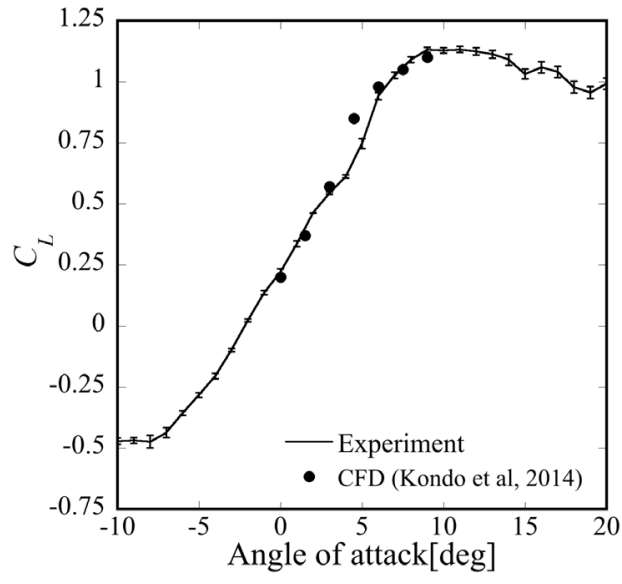

(a)

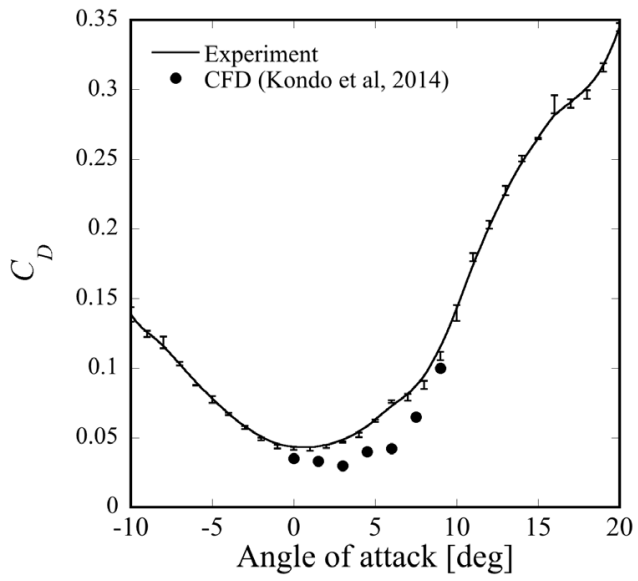

(b)

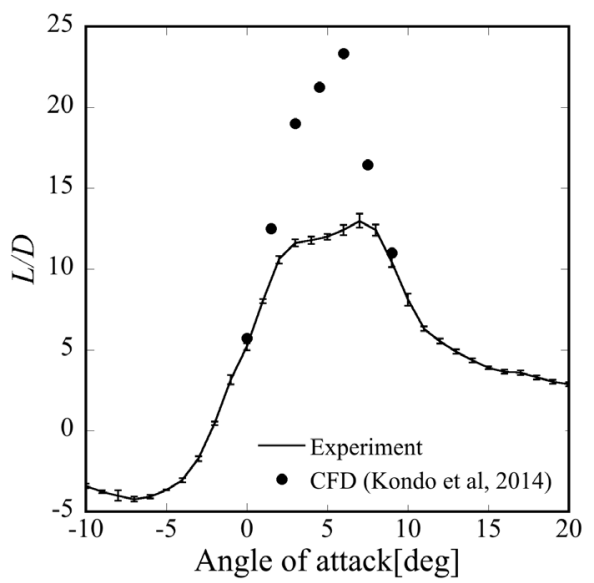

(c)

Figure 3. Aerodynamic characteristics at $R e=23,000$. (a) Lift coefficients; (b) Drag coefficients; (c) Lift to drag ratio. 
linearly at low angles of attack from $\alpha=-5$ deg to $4 \mathrm{deg}$. A conventional symmetric airfoil, such as the NACA0012, at low angles of attack (around Re = 20,000 ) has a lift curve slope that is much lower than $2 \pi \alpha$ due to trailing-edge separation on its suction side and attached flow on its pressure side [18]. In contrast, the lift curve in Figure 3(a) for the test model nearly equaled to $2 \pi \alpha$ with a convex slope that rose steadily from $\alpha=0$ deg to $4 \mathrm{deg}$. Presumably, variations in the flow field around the airfoil affected the aerodynamics (to be described later). A nonlinear lift increase was observed in the range between $\alpha=4$ deg and $\alpha$ $=6 \mathrm{deg}$ where the experimental and CFD results diverged. The lift curve slope began flattening out at $\alpha>6 \mathrm{deg}$, and the lift coefficient reached almost the maximum value at $\alpha=9 \mathrm{deg}$, corresponding to the stall angle of attack. At larger angles of attack, conventional stall phenomena accompanied by a rapid lift reduction found at high Reynolds numbers was not observed here. Lift coefficients were almost the same or showed a modest decrease.

The difference in the drag coefficients between the experimental and CFD data was relatively significant. The measured drag force is only approximately 0.01 $\mathrm{N}$, which is a minute force outside the guaranteed range of the microforce balance system that we used. In our preliminary force-calibration test, the linearity between the voltage and the drag force is sufficiently ensured at around $0.01 \mathrm{~N}$. However, it is considered to be a region where drag force measurement becomes difficult due to deterioration of a signal-to-noise ratio. Although measurement error and the two-dimensional laminar-flow assumption in the CFD result might be accounted for in the results, we deduced that the most likely explanation for the difference in drag forces is the difference in their thickness at the trailing edge. As described above, the experimental test model had a thickness of $1.25 \%$ at the trailing edge. A strong negative pressure region formed on the surface, which is attributed to the thickness at the trailing edge, and thereby acted as a backpressure causing an increase in the drag force. Consequently, the experimental drag coefficients are larger than that of the CFD as shown in Figure 3(b). The drag coefficients gradually increased from $\alpha=4$ deg where the lift coefficients start to increase nonlinearly, and a kink point is observed at $\alpha=6 \mathrm{deg}$ having a similar characteristic to a drag bucket. The drag coefficients sharply increased as the angle of attack increased after the stall. The lift to drag ratios $(L / D)$ plotted in Figure 3(c) also showed marked differences between the experimental and CFD results, which were due to differences in their drag coefficients. The maximum $L / D$ reached about 13.0 at $\alpha=7 \mathrm{deg}$ in the experimental data. Furthermore, between $\alpha=2 \mathrm{deg}$ and $\alpha=9 \mathrm{deg}$, below the stall angle of attack, the $L / D$ maintained a high value of about $80 \%$ of the $L / D_{\max }$.

Figure 4 shows Reynolds number dependency on the aerodynamic performance from $\operatorname{Re}=23,000-60,000$. Figure 4 (a) shows plots of the lift coefficient as a function of the angle of attack for five Reynolds values. Up to around $\alpha=2$ deg, the plots show a linear slope with little variation between the Reynolds numbers. Above that, the plots begin to diverge and assume a non-linear slope 


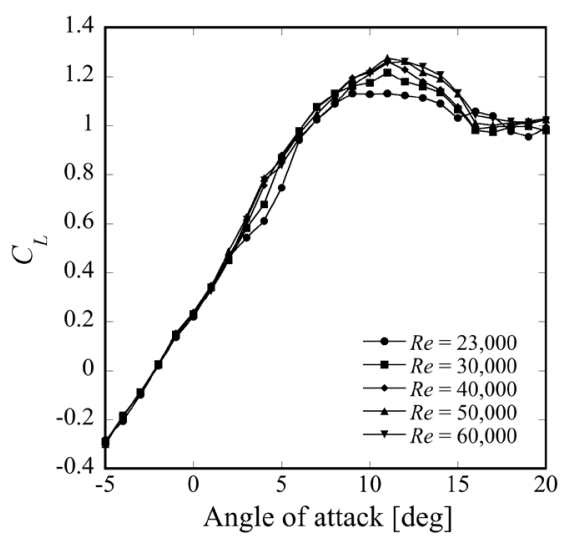

(a)

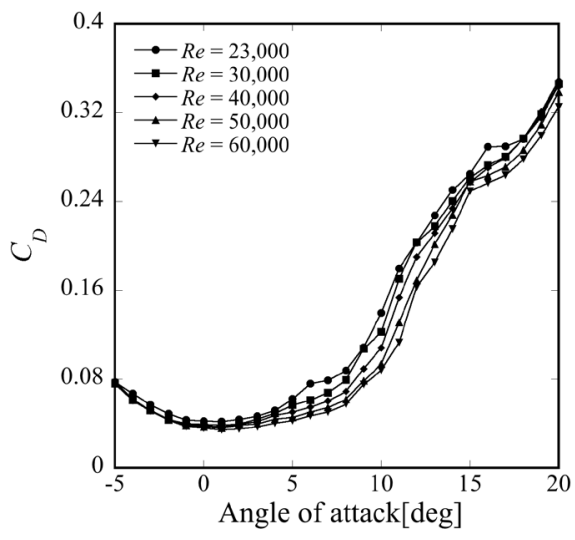

(b)

Figure 4. Reynolds number dependency on aerodynamic performance. (a) Lift coefficients; (b) Drag coefficients.

to eventually flatten out or dip at $\alpha>6 \mathrm{deg}$. At high angles of attack above $\alpha=9$ deg, the plots diverge again and the maximum lift coefficient increases with Reynolds number. The relation between Reynolds number and the maximum lift to drag ratio $\left(L / D_{\max }\right)$ is illustrated in Figure 5 . The $L / D_{\max }$ gradually increased in proportion to the Reynolds number. In particular, an increment of the $L / D_{\max }$ from $\operatorname{Re}=23,000$ to 30,000 is the largest, and the $L / D_{\max }$ almost linearly increases above $\operatorname{Re}=30,000$. By contrast, the drag curves shown in Figure 4(b) have Reynolds number dependency, and the drag characteristics tended to decrease gradually with a decrease in the Reynolds number since the viscous drag relatively increased with a decreasing Reynolds number compared with the pressure drag.

\subsection{Flow Field around Airfoil at $\operatorname{Re}=23,000$}

Visualization of the flow fields on the suction side of the airfoil by a smoke wire method at $\operatorname{Re}=23,000$ from $\alpha=1 \mathrm{deg}$ to $13 \mathrm{deg}$ is shown in Figure 6. Here a separation, transition, and reattachment are denoted by $\mathrm{S}, \mathrm{T}$, and $\mathrm{R}$, respectively. At $\alpha=1$ deg [Figure 6(a)], the flow separated near the trailing edge, and the separation point gradually moved toward the leading edge as the angle of attack increased until $\alpha=4$ deg [Figure 6(b)]. The separated shear layer transitioned from laminar to turbulent and reattached to the surface at $\alpha=5$ deg [Figure $6(c)]$. Then, a separation bubble formed between the separation and reattachment points. Since a large negative pressure region on the suction side was formed inside the separation bubble [19], we attributed the nonlinear lift increase in Figure 3(a) to the formation of the separation bubble. The drag coefficients also increased at around $\alpha=5$ deg due to the increase in pressure drag associated with the formation of the separation bubble on the suction side. This separation bubble advanced to the leading edge as the angle of attack increased. However, after the separation point passed near the maximum airfoil thickness at $\alpha=8 \mathrm{deg}$ [Figure 6(e)], a short separation bubble formed near the leading 


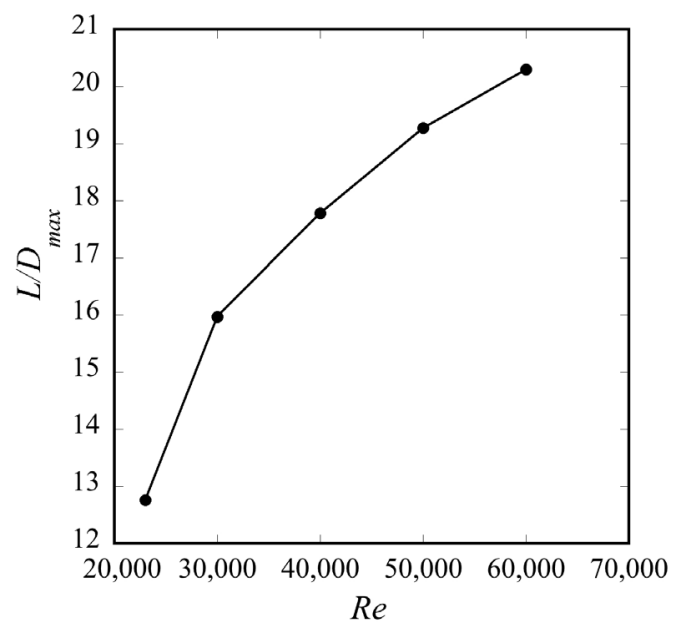

Figure 5. Reynolds number vs. $L / D_{\max }$.

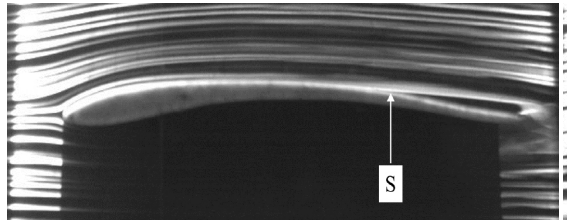

(a)

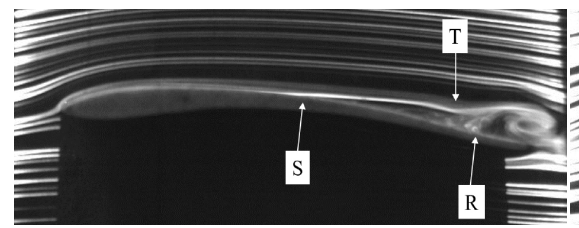

(c)

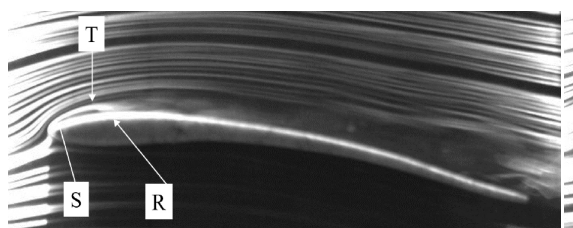

(e)

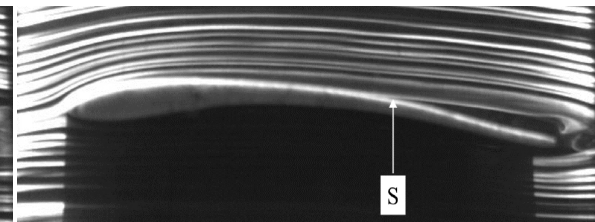

(b)

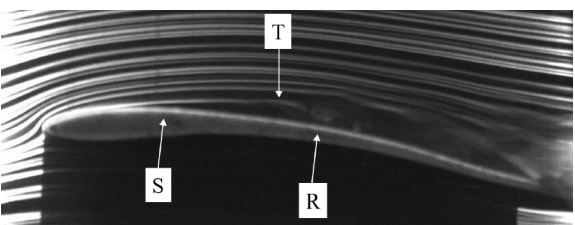

(d)

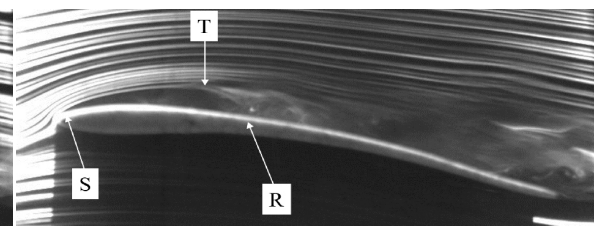

(f)

Figure 6. Flow visualization on suction side at $\operatorname{Re}=23,000$. (a) $\alpha=1 \mathrm{deg}$; (b) $\alpha=4 \mathrm{deg}$; (c) $\alpha=5 \mathrm{deg}$; (d) $\alpha=6 \mathrm{deg}$; (e) $\alpha=8 \mathrm{deg}$; (f) $\alpha=10 \mathrm{deg}$.

edge. Although the separation point remained fixed at the leading edge, the reattachment point gradually moved to the trailing edge, and the separation bubble stretched [Figure 6(f)]. The flow clearly separated at the leading edge without reattachment above $\alpha=12$ deg [Figure 6(g)], and large-scale vortices shed downstream. However, the lift coefficient at around $\alpha=12$ deg did not decrease much as shown in Figure 3(a) despite dramatic changes in the flow field such as the burst of the separation bubble. It is inferred that a high negative pressure region is secured on the suction side after the burst by exchanging momentum due to the mixing of the shedding vortices. The characteristics of the flow fields on the suction side at $\operatorname{Re}=23,000$ are summarized in Table 2 . 
Table 2. Corresponding Reynolds number and flow velocity.

\begin{tabular}{cccc}
\hline Angle of attack $(\alpha)[\mathrm{deg}]$ & $1 \leq \alpha \leq 4$ & $5 \leq \alpha \leq 11$ & $12 \leq \alpha$ \\
\hline Flow field & $\begin{array}{c}\text { Trailing-edge } \\
\text { separation }\end{array}$ & $\begin{array}{c}\text { Formation of } \\
\text { separation bubble }\end{array}$ & $\begin{array}{c}\text { Leading-edge } \\
\text { separation }\end{array}$ \\
\hline
\end{tabular}

Figure 7 shows the flow fields at $\mathrm{Re}=30,000$. Compared with Fig. 6 , the flow fields on the suction side at $\alpha=1,6,8$ degrees are almost the same even if the Reynolds number increases. Since there is almost no Reynolds number dependency on the aerodynamic performance at the corresponding angles of attack as shown in Figure 4, we assume that the flow field is similar in larger Reynolds number region.

The flow fields on the pressure side of the airfoil at $\mathrm{Re}=23,000$ are shown in Figure 8. It is significant that the separation bubble formed on the pressure side at $\alpha=0 \mathrm{deg}$ (Figure 8(a)). The flow separated at around $x / c=0.1$ and reattached to the surface near the center of the chord length with turbulent transition, thus thickening the separated shear layer. The location and length of the separation bubble changed little, but the state of the turbulent transition gently changes with the angle of attack [Figures 8 (b)-(c)]. Furthermore, the boundary layer gradually thinned out. The flow field on the pressure side changed to almost attached flow at $\alpha=5$ deg [Figure 8(d)].

At $\alpha=5 \mathrm{deg}$, the position of the separation bubble switched from the pressure side to the suction side. This tendency is very similar to the property observed in a circular arc airfoil [20] where the separation bubble is continuously present on the airfoil surface within a wide angle of attack range. The difference in lift at low angles of attack between the aforementioned NACA0012 airfoil and the owl airfoil corresponded to the presence and absence of the separation bubble on the lower surface. The positive pressure region on the pressure side inside the separation bubble worked to enhance the lift. In addition, the drag increase was not distinctly observed from $\alpha=0$ deg to 4 deg, as shown in Figure 3(b), despite the increase in pressure drag associated with the laminar separation on the pressure side near the leading edge. We deduced that the impact of the separation bubble thickness on the projected area viewed from the front was limited to low angles of attack because of the characteristically large undercamber shape line of the owl airfoil. Furthermore, the positive pressure region on the pressure side where the undercamber was strong worked in the thrust direction and had the effect of decreasing the drag. Therefore, the separation bubble formed on the pressure side during the low angles of attack contributed greatly to the lift increase such that drag was curbed.

\section{Conclusions}

In this study, we performed aerodynamic measurements and flow visualizations of the smooth owl-like airfoil without serrations and velvet structures at low Reynolds numbers using a low-speed wind tunnel. The Reynolds number dependency 


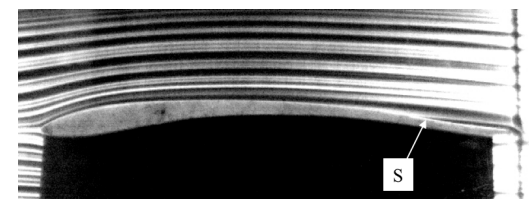

(a)

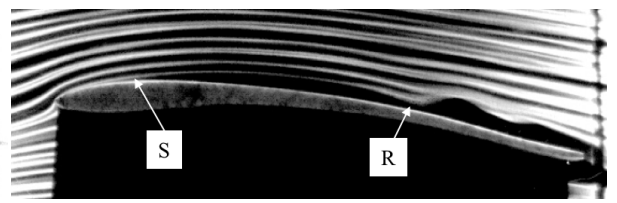

(b)

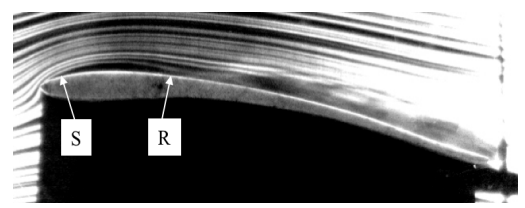

(c)

Figure 7. Flow visualization on suction side at $\operatorname{Re}=30,000$. (a) $\alpha=1 \mathrm{deg}$; (b) $\alpha=6 \mathrm{deg}$; (c) $\alpha=8 \mathrm{deg}$.

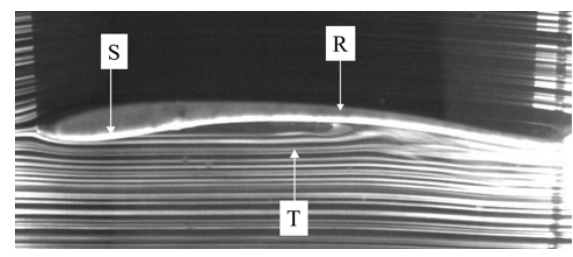

(a)

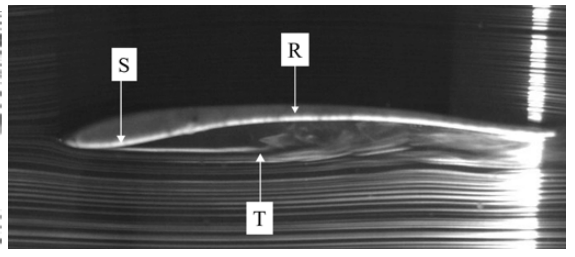

(b)

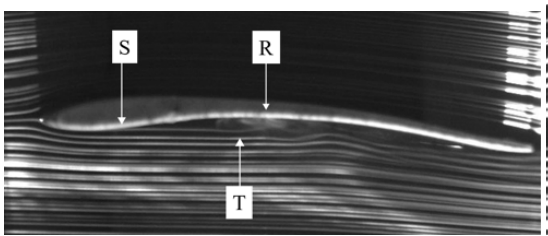

(c)

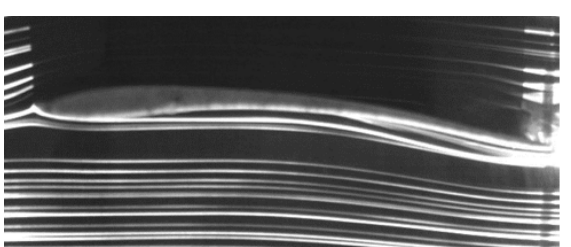

(d)

Figure 8. Flow visualization on pressure side at $\operatorname{Re}=23,000$. (a) $\alpha=0$ deg; (b) $\alpha=2$ deg; (c) $\alpha=4 \mathrm{deg}$; (d) $\alpha=5 \mathrm{deg}$.

on the aerodynamic performance was also evaluated for $\operatorname{Re}=23,000-60,000$.

Compared with a conventional symmetric airfoil such as the NACA0012 airfoil, the owl airfoil had much higher lift performance at $\operatorname{Re}=23,000$ with a nonlinear lift increase from $\alpha=4$ deg to $\alpha=6$ deg due to the formation of the separation bubble on the suction side. A distinctive flow feature was a separation bubble formed on the pressure side at low angles of attack. The presence or absence of the separation bubble on the pressure side was largely attributed to differences in aerodynamics between the NACA0012 airfoil and the owl airfoil. Furthermore, the position of the separation bubble switched from the pressure side to the suction side at $\alpha=5 \mathrm{deg}$, and was continuously present on the airfoil surface at wide-ranging angles of attack. In particular, the separation bubble on the pressure side contributed greatly to lift increase while curbing drag as the positive pressure region inside the separation bubble on the pressure side at the strong undercamber position reduced the drag at low angles of attack. The Reynolds number dependency on the lift curves was not large, although differences in the drag curves became more pronounced with higher angles of attack at $\alpha>5$ 
deg.

In general, increase in pressure drag is associated with a laminar separation or formation of a separation bubble on the pressure side. Hence, to reduce drag, these types of flow phenomena would need to be suppressed. However, the owl airfoil exhibited high lift to drag ratios using its strong undercamber, especially from $x / c=0.2$ to 0.6 , and thereby taking advantage of the separation bubble on the pressure side. Information from these experiments will prove to be useful to aerodynamic studies of low-Reynolds-number biomimetic wings and flapping wings for MAVs.

\section{Acknowledgements}

We would like to sincerely thank Mitsuru Ishii for providing the test model. We would like to thank Mitsuru Nakauchi and Yuuki Ohkubo, who are current students at Kyushu University, for their contribution to this research.

\section{References}

[1] Alan, S.H., Paul, T.S. and Richard, E.H. (1974) Investigation of Acoustic Effects of Leading-Edge Serrations on Airfoils. Journal of Aircraft, 11, 197-202. https://doi.org/10.2514/3.59219

[2] Lilly, G.M. (1998) A Study of the Slight Flight of the Owl. 4th AIAA/CEAS Aeroacoustics Conference, AIAA Paper 98-2340, 1-6. https://doi.org/10.2514/6.1998-2340

[3] Wagner, H., Weger, M., Klaas, M. and Schröder, W. (2017) Features of Owl Wings that Promote Silent Fight. Interface Focus, 7, Article ID: 20160078. http://dx.doi.org/10.1098/rsfs.2016.0078

[4] Winzen, A., Klän, S., Klaas, M. and Schröder, W. (2012) Flow Field Analysis and Contour Detection of a Natural Owl Wing Using PIV Measurements. Nature-Inspired Fluid Mechanics: Results of the DFG Priority Programme 1207 "Nature-Inspired Fluid Mechanics” 2006-2012. Springer, Berlin, 119-134. https://doi.org/10.1007/978-3-642-28302-4_7

[5] Mueller, T.J., Kellogg, J.C., Ifju, P.G. and Shkarayev, S.V. (2007) Introduction to the Design of Fixed-Wing Micro Air Vehicles: Including Three Case Studies. AIAA Education Series, Reston. https://doi.org/10.2514/4.862106

[6] Braun, R.D. and Spencer, D.A. (2006) Design of the ARES Mars Airplane and Mission Architecture. Journal of Spacecraft and Rockets, 43, 1026-1034. https://doi.org/10.2514/1.17956

[7] Nagai, H. and Mars Airplane, W.G. (2015) Aerodynamic Challenge to Realize Mars Airplane. 30 th International Symposium on Space Technology and Science, Kobe, Japan, 2015-k-47, 1-6.

[8] Liu, T., Kuykendoll, K., Rhew, R. and Jones, S. (2006) Avian Wing Geometry and Kinematics. AIAA Journal, 44, 954-963. https://doi.org/10.2514/1.16224

[9] Schmitz, F.W. (1976) Aerodynamic of the Model Airplane Part 1. NASA TM-X-60976.

[10] Schmitz, F.W. (1980) The Aerodynamics of Small Reynolds Number. NASA TM-51.

[11] Bachmann, T. and Wagner, H. (2011) The Three-Dimensional Shape of Serrations at Barn Owl Wings: Towards a Typical Natural Serration as a Role Model for Biomimetic Applications. Journal of Anatomy, 219, 192-202. 
https://doi.org/10.1111/j.1469-7580.2011.01384.x

[12] Kondo, K., Aono, H., Nonomura, T., Anyoji, M., Oyama, A., Liu, T., Fujii, K. and Yamamoto, M. (2014) Analysis of Owl-like Airfoil Aerodynamics at Low Reynolds Number Flow. Transactions of the Japan Society for Aeronautical and Space Sciences, 12, Tk 35-Tk 40. https://doi.org/10.2322/tastj.12.Tk_35

[13] Anyoji, M., Nonomura, T., Aono, H., Oyama, A., Fujii, K., Nagai, H. and Asai, K. (2014) Computational and Experimental Analysis of a High-Performance Airfoil under Low-Reynolds-Number Flow Condition. Journal of Aircraft, 51, 1864-1872. https://doi.org/10.2514/1.C032553

[14] O’Meara, M.M. and Mueller, T.J. (1987) Laminar Separation Bubble Characteristics on an Airfoil at Low Reynolds Number. AIAA Journal, 25, 1033-1041. https://doi.org/10.2514/3.9739

[15] Mueller, T.J. and Batill, S.M. (1982) Experimental Studies of Separation on a Two-Dimensional Airfoil at Low Reynolds Number. AIAA Journal, 20, 457-463. https://doi.org/10.2514/3.51095

[16] Rae Jr., W.H. and Pope, A. (1984) Low-Speed Wind Tunnel Testing. 2nd Edition, John Wiley \& Sons Inc., New York.

[17] Burns, T.F. and Mueller, T.J. (1982) Experimental Studies of the Eppler 61 Airfoil at Low Reynolds Numbers. 20th Aerospace Science Meeting, Orland, 11-14 January 1982, AIAA Paper 82-0345. https://doi.org/10.2514/6.1982-345

[18] Kojima, R., Nonomura, T., Oyama, A. and Fujii, K. (2013) Large-Eddy Simulation of Low-Reynolds-Number Flow over Thick and Thin NACA Airfoils. Journal of Aircraft, 50, 187-196. https://doi.org/10.2514/1.C031849

[19] Tani, I. (1964) Low-Speed Flows Involving Bubble Separations. Progress in Aerospace Sciences, 5, 70-103. https://doi.org/10.1016/0376-0421(64)90004-1

[20] Okamoto, M. (2006) An Experimental Study on Aerodynamic Characteristics of Steady and Unsteady Airfoil at Low Reynolds Number. Ph.D. Thesis, Nihon University, Tokyo. 


\section{Nomenclature}

$b$ : Span of a real owl wing

c. Chord length $[\mathrm{m}]$

$C_{D}$ : Drag coefficient

$C_{L}$ : Lift coefficient

$D$ : Drag [N]

$L$ : Lift [N]

Re: Reynolds number

$t$. Test model thickness [m]

$x$. Chordwise coordinate

$y$. Vertical coordinate

z. Spanwise coordinate

$\alpha$ : Angle of attack [deg] 